\title{
Efficacy of beehive fences as barriers to African elephants: a case study in Tanzania
}

\author{
Ciska P.J. Scheijen, Shane A. Richards, Josephine Smit \\ TREVOR JONES and KataRZYNA NOWAK
}

\begin{abstract}
Non-lethal mitigation of crop use by elephants Loxodonta africana is an increasingly important part of protected area management across Africa and Asia. Recently, beehive fences have been suggested as a potential mitigation strategy. We tested the effectiveness of this method in a farming community adjacent to Udzungwa Mountains National Park in southern Tanzania. Over a 5.5-year period (2010-2016) a beehive fence was introduced and subsequently extended along the Park boundary. The probability that one or more farms experienced crop loss from elephants on a given day was reduced in the presence of the fence and was reduced further as the fence was extended. The number of hives occupied by bees along the fence was the best predictor of elephants' visits to farms. Farms closest to the fence experienced a greater likelihood of damage, particularly during the initial period when the fence was shorter. The number of farms affected by elephants declined when the fence was extended. There was a higher probability of damage on farms that were closer to the Park boundary and further from a road. Our mixed results suggest that the shape, length and location of fences need to be carefully planned because changes in a farm's long-term susceptibility to elephant damage vary between individual farms; fences need to be long enough to be effective and ensure that decreasing crop loss frequency is not outweighed by an increasing number of farms damaged per visit.
\end{abstract}

Keywords Beehive fences, crop use, elephants, humanwildlife interactions, Loxodonta africana, mitigation, Tanzania, Udzungwa

Ciska P. J. Scheijen ${ }^{\star}$ Department of Wildlife Management, Van Hall Larenstein University of Applied Sciences, Leeuwarden, The Netherlands

Shane A. Richards $\uparrow$ School of Natural Sciences, University of Tasmania, Sandy Bay, Australia

JosePhine Smit $\ddagger$ Department of Psychology, University of Stirling, Stirling, UK

Trevor Jones Southern Tanzania Elephant Program, Iringa, Tanzania

KATARZYNA NoWAK $\$$ (Corresponding author) Zoology \& Entomology, University of the Free State, Qwaqwa Campus, Phuthaditjhaba, 9866, South Africa E-mail knowak02@gmail.com

*Also at: Animal, Wildlife, and Grassland Sciences, University of the Free State, Bloemfontein, South Africa

$\dagger$ Also at: Oceans \& Atmosphere, Commonwealth Scientific and Industrial Research Organisation, Hobart, Australia

$\ddagger$ Also at: Southern Tanzania Elephant Program, Iringa, Tanzania

Received 20 April 2017. Revision requested 16 June 2017.

Accepted 13 November 2017. First published online 21 May 2018.

\section{Introduction}

Tegative interactions between elephants Loxodonta 1 africana and people are a major concern for wildlife management and rural development initiatives across Africa (Osborn \& Parker, 2003; Sitati et al., 2003; King et al., 2011). There are different kinds of such negative interactions (Nelson et al., 2003; Sitati et al., 2003), with one of the most prevalent being agricultural crop-use by elephants (Sitati et al., 2005; Graham et al., 2010). Crop exploitation often occurs in areas where agricultural activities take place close to protected areas (Shemwetta \& Kidegesho, 2000; Nelson et al., 2003; Osborn \& Parker, 2003; Sitati \& Walpole, 2006; Hedges \& Gunaryadi, 2010), or where former elephant corridors are interrupted by human settlements, agricultural fields, and plantations (Nelson et al., 2003; Jones et al., 2012; Gunn et al., 2014). The results include economic losses for farmers (Hoare, 2000; Hedges \& Gunaryadi, 2010; King et al., 2009; Jadhav \& Barua, 2012), and loss of human (Hedges \& Gunaryadi, 2010; Jadhav \& Barua, 2012) and elephant (Hedges \& Gunaryadi, 2010) lives. These outcomes have socio-political implications (King et al., 2009; Jadhav \& Barua, 2012) that influence conservation decisions and solutions, e.g. elimination of so-called problem elephants by wildlife agencies (Stephenson, 2007). However, problem animal control has proven largely ineffective as a long-term solution to negative interactions between people and elephants, as individual animals can be one-off or occasional rather than habitual crop users (Stephenson, 2007; Chiyo et al., 2012; Smit et al., 2017).

Mixed conservation strategies that combine management (e.g. deterrence of elephants from crops and human settlements, crop insurance schemes) with income-enhancing activities (e.g. honey production, pollination services, and small-scale nature tourism) have been proposed (Osborn \& Parker, 2003; King et al., 2011) to deal with these economic, socio-political and conservation conflicts. Projects implemented by international organizations can fail because of the low overall benefits accrued from crop protection and the return investment needed from the organizations driving the crop-damage mitigation efforts (Osborn \& Parker, 2003). Therefore, local self-help groups and farmer-led projects that yield economic and social benefits are often favourable and longer-lasting (Omondi et al., 2004).

Beehive fencing is a novel method for mitigating the frequency and intensity of human-elephant contact and has been effective in northern Kenya (King et al., 2011, 2017). 
There is evidence that such fences significantly reduce crop losses from elephants, whilst also providing an income stream for farmers who harvest and sell honey and other bee products. Elephants avoid disturbed African honeybees Apis mellifera scutellata, which they probably encounter regularly in the wild (King et al., 2007). Elephants move away from bee sounds, make alarm calls to warn family members of potential threats posed by bees, and keep a safe distance of $>4 \mathrm{~m}$ from beehives (King et al., 2009). Based on these findings, the efficacy of a fence with hives placed $10 \mathrm{~m}$ apart as an elephant deterrent has been tested (King et al., 2011). Farms in Kenya were either semi-encircled with a $1,700 \mathrm{~m}$ beehive fence combined with thorn bush barriers or encircled with a thorn bush barrier only. Of 45 visits to farms by elephants, only one involved an elephant breaching the beehive fence, whereas the thorn barriers were broken 31 times. Following successful farm foraging events, elephants returned more often to farms encircled with thorn bushes than to farms with a beehive fence (King et al., 2011). The most recent study of beehive fences, where real hives were alternated with two-dimensional dummy hives to reduce costs, showed them to be effective in deterring elephants $80 \%$ of the time (King et al., 2017).

As well as mitigating negative elephant-human interactions, beehive fences can also contribute to sustainable development by providing alternative revenue streams, which can reduce the impact of crop damage and the necessity for lethal control methods (King et al., 2011). Furthermore, because Kenyan top-bar hives are easy to construct and maintain, farmers may prefer to invest in beehive fences (King et al., 2011) rather than in other mitigation methods such as chilli-oil fences, which require higher maintenance and provide little or no additional financial benefits (Osborn \& Parker, 2003; Graham \& Ochieng, 2008; Chelliah et al., 2010). Electric fences have also been evaluated as a deterrent (Osborn \& Parker, 2003; Adjewodah et al., 2005; Kioko et al., 2008; King et al., 2011), but they are often impractical in remote, rural areas and their installation and maintenance costs can be prohibitive (Osborn \& Parker, 2003; King et al., 2011).

Here we evaluate the effectiveness of a beehive fence in reducing crop-use by elephants in a remote forest site in southern Tanzania. Rather than fencing that semi-encircled the farms, we investigated the effect of a single linear fence constructed at a location frequently used by elephants. Our study site was located along the eastern boundary of the Udzungwa Mountains National Park, where there is no buffer zone between the forest and adjacent farms (Nowak et al., 2009; Kabepele, 2011; Smit et al., 2017). In this area former elephant corridors have been blocked by human settlements in recent years (Jones et al., 2012), resulting in increased crop use by elephants (Jones \& Nowak, pers. obs.; Nowak et al., 2009). We present and analyse elephant crop foraging data over a 5.5-year period (2010-2016) that spanned phases with no fence, a short and a long fence. We examined the effects of fence presence and length on elephant visit frequency and on the number of farms damaged during these visits.

\section{Methods}

\section{Study site}

The study area encompassed two villages, Mang'ula A and Mang'ula B. These villages are located at the base of the eastfacing escarpment of the Udzungwa Mountains National Park, in the Kilombero Valley, south-central Tanzania (Bowkett et al., 2008; Kabepele, 2011; Fig. 1). In 2012 the elephant population of the Udzungwa Mountains was estimated at c. 500-1,000 (Southern Tanzania Elephant Program, unpubl. data). Resident elephants in the Park are found up to the highest peaks $(2,400 \mathrm{~m})$ where they forage on bamboo and find refuge from human threats (Kabepele, 2011; Jones \& Nowak, 2015). Along the eastern side of the Park, lowland rainforest and miombo woodland extend to the Park boundary, and there is no buffer zone between the forest edge and the adjacent farms. The wet season is November-May and there is a drier and colder period during June-October (Lovett et al., 2006). Annual precipitation is 1,200-1,800 mm; mean monthly rainfall is $28 \mathrm{~mm}$ in the dry season and $238 \mathrm{~mm}$ in the wet season (Harchut et al., 2013).

There are c. 150 farms of $0.25-2$ ha associated with the two villages. Water is plentiful year-round, with several rivers flowing off the forested mountains and some of the farmers using irrigation. The farmers grow c. 40 types of crops, and most of them mix crops in the available space (mixed intercropping; Sullivan, 2003). Farms contain similar combinations of crops, including spinach, okra and tomatoes, but in varying amounts. Almost all farms are affected by elephants eating or trampling crops, and crop loss mitigation methods, including fire, noise and covering crops with elephant dung, were used sporadically before and during the study period. A chilli-oil fence was deployed in 2009 but abandoned in 2010 because it was difficult to maintain and offered no additional benefits to farmers. Forty-eight crop-using elephants were identified at the site during 2010-2014 (Smit et al., 2017), all of them males, with c. two-thirds occasional crop users that were detected only once and the others repeat crop users detected multiple times during this period. Other species also cause crop losses, including bush pigs Potamochoerus larvatus, yellow baboons Papio cynocephalus cynocephalus, several other monkey species (e.g. Sykes' monkeys Cercopithecus mitis), crested porcupines Hystrix cristata, birds, insects and rodents (Kabepele, 2011), but these losses were on a smaller scale compared to the damage caused by elephants.

\section{Beehive fences}

Elephant-caused crop damage was observed during three consecutive time periods. Firstly, we observed damage 


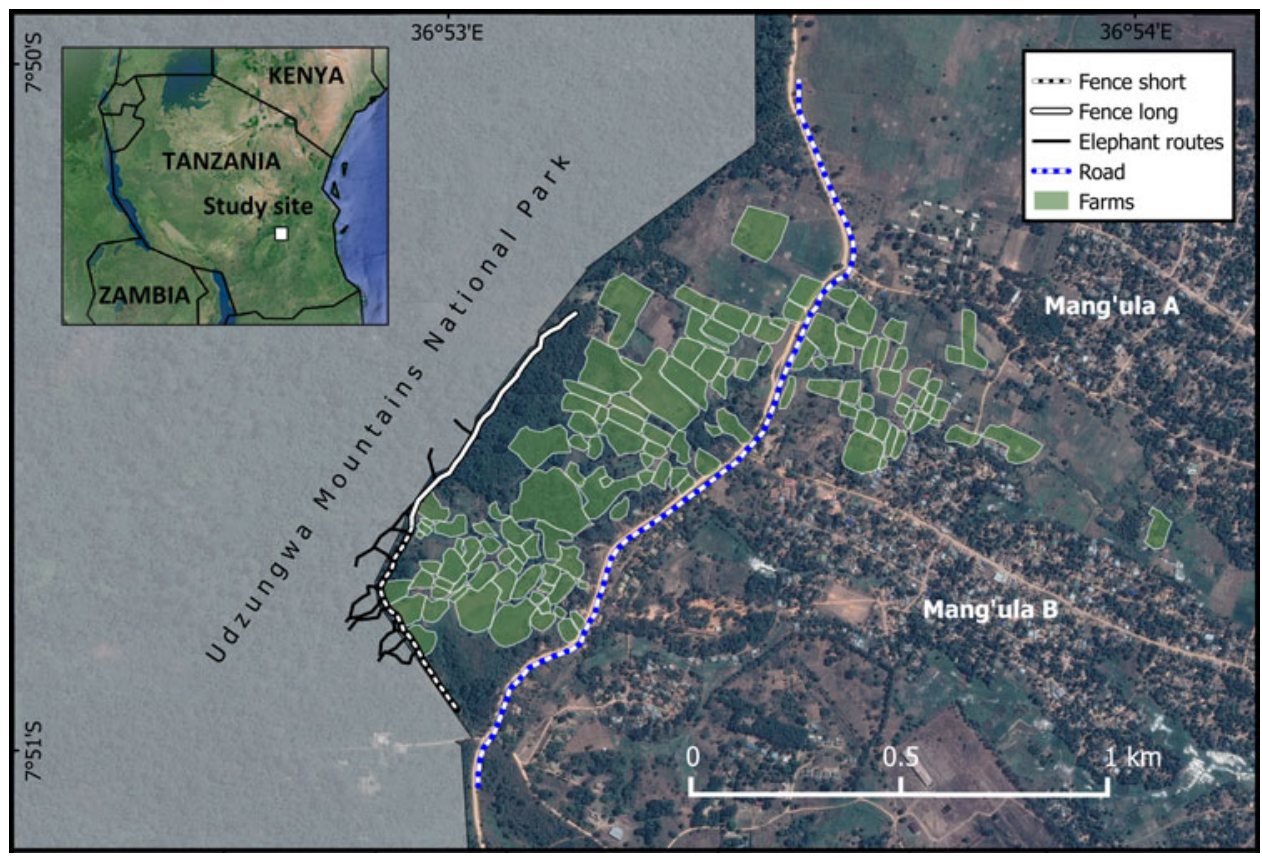

FIG. 1 Study area with the two focal villages Mang'ula A and Mang'ula B along the eastern boundary of Udzungwa Mountains National Park. All 120 farms included in our analysis are shown, as is the main road, elephant routes, and the short and long beehive fences. Map data are from Google imagery (2017).

from August 2010-November 2011 (16 months) when no beehive fence was present (the 'absent fence' stage). A beehive fence with a length of initially $500 \mathrm{~m}$ and with 50 hives ('short fence') was constructed in November 2011, using a Beehive Fence Construction Manual developed in Kenya (King, 2011). Kenyan top-bar beehives were hung $10 \mathrm{~m}$ apart on strong fencing wire between wooden poles and were subsequently colonized by wild bees. The individual hives were connected with wire, so an elephant trying to pass between them would cause them to swing and incite bees to fly out in defence. Each hive had a roof to protect it from rain and sun. The cost of constructing the fence was TZS 9,130 (USD 4.25) per m (Table 1).

The fence was erected in the south-western corner of the study area, near the elephants' preferred routes into farms (Fig. 1) and where elephant visits occurred most frequently (Kabepele, 2011). It was placed c. 10 m outside the Park and followed its boundary. Damage to crops was monitored until March 2014 (29 months). The fence was then extended to the north by $600 \mathrm{~m}$, also c. 10 m outside of the Park boundary, adding 87 hives ('long fence'; Fig. 1), and damage was monitored until January 2016 (22 months). The fence was constructed collaboratively by a local group of farmers (Njokomoni Farmers Group) and members of the Southern Tanzania Elephant Program. The farmers maintain the fence and, having received beekeeping training, harvest honey and wax from the beehives. The number of hives occupied by bees was monitored monthly following the contruction of the fence. Elephant crossings of the fence were monitored 6 days per week from December 2013 onwards, with data collected on the location of fence crossings and whether these occurred between occupied or unoccupied hives.
TABLE 1 Beehive fence construction costs, expressed per beehive. The length occupied by a beehive and poles is $3 \mathrm{~m}$, and each beehive is connected to $7 \mathrm{~m}$ of wire.

\begin{tabular}{lrr}
\hline Item & $\mathrm{TSH}^{1}$ & $\mathrm{USD}^{2}$ \\
\hline Beehive (Kenyan Top Bar) & 68,750 & 32.02 \\
Metal wire $(12 \mathrm{~m})$ & 7800 & 3.02 \\
Wooden poles $(2.1 \mathrm{~m})$ & 14,000 & 6.52 \\
Cement $(5 \mathrm{~kg})$ & 1,500 & 0.70 \\
Paint $(1.8 \mathrm{l})$ & 550 & 0.26 \\
Total & 92,600 & 42.52 \\
\hline
\end{tabular}

${ }^{1}$ Cost of items in Morogoro region, Tanzania in mid 2016.

${ }^{2}$ Exhange rate of USD $\$ 1=$ TSH 2,147 (average exchange rate for mid 2016).

\section{Measuring elephant visits to farms}

Only farms that were visited by elephants at least once during the data collection period were included in our analysis (120 farms). A visit is defined as a 24 -hour period during which at least one farm was affected by elephants. To detect crop damage we walked along the forest-farm interface 6 days per week, looking for fresh elephant signs (e.g. dung, footprints or feeding debris). Farmers also reported crop damage to us by telephone text message and received a phone voucher worth TZS 500 (USD 0.23) in return. Any reported crop damage was confirmed by two local research assistants with detailed knowledge of the area, farming practices, crops grown and the signs of elephant visits and damage. Days without reported damage or detected signs of elephant visits were recorded as non-visit days.

The perimeter of each affected farm was measured using a Global Positioning System (GPS) device and farm surface 
area was calculated using MapSource v. 6.16.3 (Garmin, Olathe, USA).

\section{Data analysis}

Our statistical analysis involved four parts. Firstly, we investigated the factors determining the probability of an elephant visit occurring on a given day. Secondly, we explored the number of farms damaged when a visit occurred. We then investigated whether the daily probability of fence breakage by elephants varied with the season. Finally, we examined how different aspects of a farm (e.g. its size and location) influenced its likelihood of being damaged during a visit.

We investigated the changes in the daily probability of visitation by elephants by fitting a logistic regression model, considering the state of the beehive fence (absent, short or long) and the number of occupied hives. We also considered a linear time-dependent term to account for any long-term trends and we incorporated a sinusoidal term with annual period to capture any seasonal effects. Model selection and the Akaike Information Criterion (AIC) were used to assess if visit probability was best described by a long-term smooth trend, the presence of the fence, or the number of occupied hives, and whether visits were also influenced by the time of year. Models were selected if their AIC value was within 6 of the minimum AIC value calculated across all models considered and if no simpler nested model had a lower AIC value (Richards, 2008).

The effect of the fence on the number of farms damaged during a visit was investigated using a general linear mixedeffects model. The date of the visit was included as a random effect and the number of farms damaged during a visit was assumed to exhibit a binomial distribution. As at least one farm was damaged during any visit, we fit the binomial model to the number of additional farms damaged on the same day. For example, if $n>1$ is how many of the 120 farms were damaged during a visit, then we looked for evidence that the state of the fence helped us predict the observation that $(n-1)$ of the other 119 farms were also damaged on the same day. A likelihood ratio test was used to determine if the number of farms damaged during a visit was related to the presence and length of the beehive fence.

We used a likelihood ratio test to look for evidence that the daily probability of fence breakage varied with season. Seasonality was incorporated by adding a sinusoidal term to a logistic model. The data strongly suggested that the probability of breakage was not independent across days. We incorporated this non-independence into our model by adding a predictor variable indicating whether or not breakage was observed the previous day.

A general linear mixed-effects model was also used to identify aspects of a farm that influenced its likelihood of
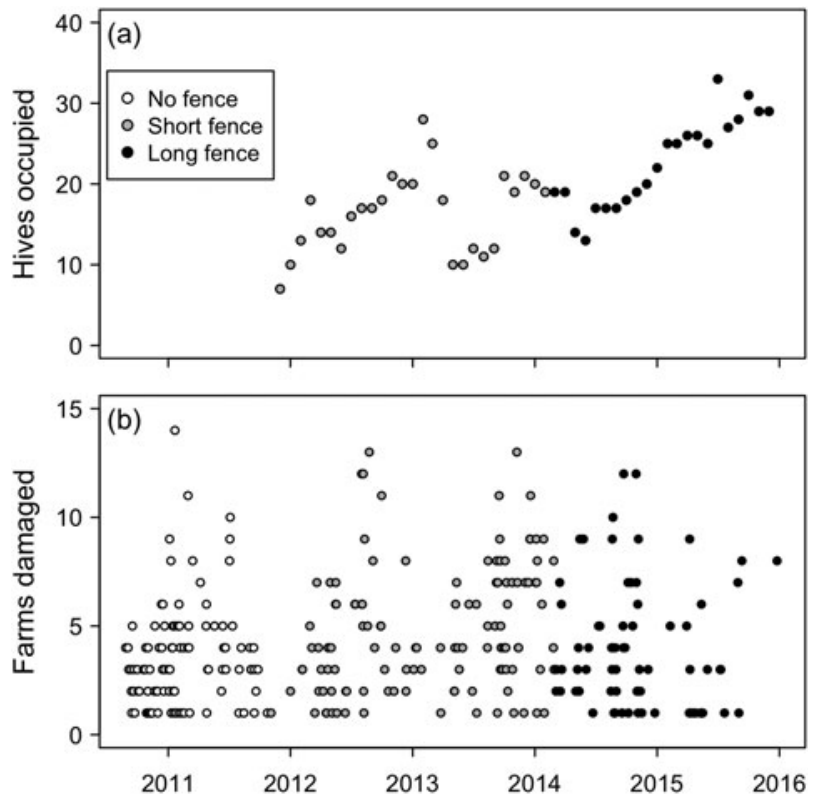

FIG. 2 (a) The number of hives occupied by bees when the hive fence was short and long. (b) The number of farms damaged during an elephant visit over time separated according to three fencing conditions: the beehive fence is absent, the presence of a short beehive fence, and the presence of a long beehive fence. Days when a visit was not observed (i.e. zero farms were damaged) are not presented, for clarity. See Figs 1 and 3 for the placement of the short and long fences.

being damaged during a visit. We considered farm area and the distances from the farm to the Park, to the beehive fence, and to the nearest road, as possible predictors of susceptibility to damage. These covariates were $\mathrm{z}$-transformed to help with fitting. A random farm effect was included to account for any unmeasured farm-dependent covariates that might have also influenced a farm's likelihood of being damaged. AIC was again used to select the most parsimonious models. All statistical analyses were performed in $R$ v. 3.3.1 (R Development Core Team, 2015), and general linear mixed-effects models were fit using the $R$ package lme 4 .

\section{Results}

Elephant crop foraging frequency declined over the course of the study (Fig. 2). The daily probabilities of crop foraging in the absence of the beehive fence, when the fence was short, and when it was long, were $0.23,0.14$ and 0.11 , respectively. The number of occupied hives increased over time, although hive uptake was slow when the fence line was extended (Fig. 2). Of the 50 hives used during construction of the short fence, 7-28 were occupied at any one time. Occupancy was 13-33 when the fence was extended. The daily probability of a visit by elephants was best explained by hive occupancy (Table 2); however, because of the positive correlations between time, fence state and hive 
TABLE 2 Akaike Information Criterion (AIC) analysis examining temporal trends in the daily probability that elephants Loxodonta africana visit farms. Three pairs of logistic models were fit to the daily data on the presence/absence of a visit by elephants. We considered a smooth long-term trend $(\mathrm{T})$, the presence of a beehive fence $(\mathrm{F})$, and the number of hives occupied by bees $(\mathrm{H})$. These models were paired with a seasonal effect (S). FS describes the effect of adding the short beehive fence, FL is the effect of extending the short fence to a long fence, $\phi$ is fractional time of year when raids are most likely, $K$ is the number of estimated parameters, LL is the maximum log-likelihood and ${ }^{*}$ indicates that the model is selected using the suggested rules outlined in Richards (2008).

\begin{tabular}{|c|c|c|c|c|c|c|c|c|c|c|c|c|}
\hline Model & $\beta_{0}$ & $\beta_{\mathrm{S}}$ & $\phi$ & $\beta_{\mathrm{T}}$ & $\beta_{\mathrm{FS}}$ & $\beta_{\mathrm{FL}}$ & $\beta_{\mathrm{H}}$ & $K$ & $\mathrm{LL}$ & AIC & AIC & Selected \\
\hline $\mathrm{T}$ & -1.04 & 0 & 0 & -0.22 & 0 & 0 & 0 & 2 & -809.5 & 1622.9 & 4.4 & * \\
\hline $\mathrm{T}+\mathrm{S}$ & -1.05 & 0.20 & 0.71 & -0.22 & 0 & 0 & 0 & 4 & -807.1 & 1622.1 & 3.6 & * \\
\hline $\mathrm{F}$ & -1.21 & 0 & 0 & 0 & -0.57 & -0.31 & 0 & 3 & -808.8 & 1623.6 & 5.0 & * \\
\hline$F+S$ & -1.24 & 0.16 & 0.72 & 0 & -0.54 & -0.32 & 0 & 5 & -807.2 & 1624.5 & 5.9 & \\
\hline $\mathrm{H}$ & -1.24 & 0 & 0 & 0 & 0 & 0 & -0.04 & 2 & -807.3 & 1618.6 & 0 & * \\
\hline $\mathrm{H}+\mathrm{S}$ & -1.26 & 0.15 & 0.77 & 0 & 0 & 0 & -0.04 & 4 & -805.9 & 1619.7 & 1.1 & \\
\hline
\end{tabular}

occupancy, all three variables predicted the data nearly equally well. There was no strong evidence of a seasonal effect on farm visitation by elephants (Table 2).

The number of farms damaged during a visit differed for the three fence states (likelihood ratio test, $G_{2}=13.22$, $\mathrm{P}=0.001)$. The mean number of farms damaged per visit when the fence was absent, short and long were 3.6, 4.9, and 4.0, respectively; only the absent-short comparison was significantly different $(\mathrm{P}<0.05)$. A farm's susceptibility to damage during a visit was by far best explained by its distance from the beehive fence when the fence was present; farms located closer to the fence were more likely to be damaged (Table 3, Fig. 3). However, after having accounted for distance from the beehive fence, there was further evidence that farms further from the Park and farms closer to a road were less likely to be damaged (Table 3, Fig. 3). A farm's susceptibility to damage was not related to its size (Table 3 ).

Between December 2013 and January 2016, elephants crossed through the fence 133 times and walked around the fence seven times ( $N=140$ visits) either on their way into farms or returning to the forest. In 92 of the 133 cases (69\%) of fence breaching, the hives on either side of the breakage point were not occupied by bees, in $26(20 \%)$ cases only one hive was occupied and in 15 cases (11\%), both hives were occupied. In 41 of the 133 cases (30\%) of elephants crossing the fence, the wire connecting the hives was missing when elephants walked through, and in 10 cases (8\%) elephants passed through gaps in the fence where hives had temporarily been removed by farmers for maintenance. We found no evidence that the probability of fence breakage varied seasonally (likelihood ratio test, $G_{2}=0.53, \mathrm{P}=0.767$ ).

\section{Discussion}

We found evidence that the erection of a beehive fence, and its subsequent extension, reduced the frequency at which farms were damaged by elephants at this forest site in southern Tanzania. However, the overall effectiveness of the beehive fence was mixed because the number of farms damaged during an elephant visit increased in the presence of the fence. In addition, we found evidence that farms located nearer the fence were more likely to be damaged when elephants entered the site.

Our observations suggest that elephants had preferred access routes to the farms from the National Park, which were probably least-cost paths that avoided the steep slopes and challenging terrain that characterize the Udzungwa Mountains. Elephants continued using these routes in the south-west part of the study area throughout the three stages of fencing (Smit et al., 2017), and elephant crop use was not transferred to other nearby villages following the fencing at our site (Southern Tanzania Elephant Program, unpubl, data). This meant that farms located near these routes (i.e. the south-west section of the study area) had elevated rates of damage independent of the presence of hives compared to farms further away from elephant access routes (Fig. 3). This pattern is consistent with observations in Kenya where elephants mainly entered those farms that they reached first upon leaving a protected area (King et al., 2017). A further explanation of increased damage near the fence line during a successful visit (Table 3) could be that elephants trample crops while they walk along the inner side of the fence until they encounter a gap or the end of the fence. This pattern is also consistent with findings from the study in Kenya where elephants were observed walking along the fence line until its end, seeking a pathway out of the farmland (King et al., 2011, 2017).

Because African honeybees are aggressive it was not practical to place fences close to where farmers were working, especially given the small size of the farms at this site. The fence was therefore erected as a linear barrier running along the Park boundary, which meant that elephants could walk along and around it, and enter farmland where the fence ended. If there were gaps in the fence, either because hives had been knocked over by elephants or because wire between hives was missing, then these could also be used by elephants to enter fields until farmers repaired these 
TABLE 3 Akaike Information Criterion (AIC) analysis examining farm traits that influence susceptibility to damage during a visit by elephants. Fits for 16 binomial regression models with a random farm effect are presented. Up to four predictor variables without interaction effects were considered: farm size (S), distance to National Park $(\mathrm{P})$, distance to beehive fence $(\mathrm{F})$ and distance to nearest road (R). Predictor variables were $\mathrm{z}$-transformed so the regression coefficients $\left(\beta_{x}\right)$ describe relative effect sizes. $\sigma$ is the standard deviation of the random effect term. $K$ is the number of estimated parameters, LL is the maximum log-likelihood and ${ }^{\star}$ indicates that the model is selected using the suggested rules outlined in Richards (2008).

\begin{tabular}{|c|c|c|c|c|c|c|c|c|c|c|c|}
\hline Model & $\beta_{0}$ & $\beta_{\mathrm{S}}$ & $\beta_{\mathrm{P}}$ & $\beta_{\mathrm{F}}$ & $\beta_{\mathrm{R}}$ & $\sigma$ & $K$ & LL & AIC & AIC & Selected \\
\hline Null & -4.09 & 0 & 0 & 0 & 0 & 1.18 & 2 & -891.5 & 1787.1 & 50.7 & \\
\hline S & -4.09 & 0.13 & 0 & 0 & 0 & 1.17 & 3 & -890.9 & 1787.8 & 51.4 & \\
\hline $\mathrm{P}$ & -4.08 & 0 & -0.39 & 0 & 0 & 1.11 & 3 & -885.6 & 1777.1 & 40.7 & \\
\hline $\mathrm{F}$ & -4.08 & 0 & 0 & -0.43 & 0 & 1.08 & 3 & -865.6 & 1737.3 & 0.9 & * \\
\hline $\mathrm{R}$ & -4.09 & 0 & 0 & 0 & 0.15 & 1.17 & 3 & -890.7 & 1787.4 & 51.0 & \\
\hline $\mathrm{S}+\mathrm{P}$ & -4.08 & 0.08 & -0.38 & 0 & 0 & 1.10 & 4 & -885.3 & 1778.6 & 42.1 & \\
\hline$S+F$ & -4.08 & 0.12 & 0 & -0.43 & 0 & 1.07 & 4 & -865.0 & 1738.0 & 1.5 & \\
\hline$S+R$ & -4.09 & 0.12 & 0 & 0 & 0.14 & 1.17 & 4 & -890.2 & 1788.3 & 51.9 & \\
\hline $\mathrm{P}+\mathrm{F}$ & -4.08 & 0 & -0.17 & -0.40 & 0 & 1.07 & 4 & -864.4 & 1736.9 & 0.5 & * \\
\hline $\mathrm{P}+\mathrm{R}$ & -4.08 & 0 & -0.41 & 0 & 0.20 & 1.09 & 4 & -884.0 & 1776.1 & 39.7 & \\
\hline $\mathrm{F}+\mathrm{R}$ & -4.08 & 0 & 0 & -0.42 & 0.15 & 1.07 & 4 & -864.7 & 1737.4 & 1.0 & \\
\hline $\mathrm{S}+\mathrm{P}+\mathrm{F}$ & -4.08 & 0.10 & -0.16 & -0.40 & 0 & 1.06 & 5 & -864.0 & 1737.9 & 1.5 & \\
\hline $\mathrm{S}+\mathrm{P}+\mathrm{R}$ & -4.08 & 0.07 & -0.40 & 0 & 0.19 & 1.09 & 5 & -883.8 & 1777.6 & 41.2 & \\
\hline$S+F+R$ & -4.08 & 0.11 & 0 & -0.42 & 0.14 & 1.06 & 5 & -864.1 & 1738.2 & 1.8 & \\
\hline$P+F+R$ & -4.08 & 0 & -0.19 & -0.39 & 0.17 & 1.06 & 5 & -863.2 & 1736.4 & 0 & * \\
\hline $\mathrm{S}+\mathrm{P}+\mathrm{F}+\mathrm{R}$ & -4.08 & 0.09 & -0.18 & -0.40 & 0.17 & 1.05 & 6 & -862.8 & 1737.6 & 1.2 & \\
\hline
\end{tabular}
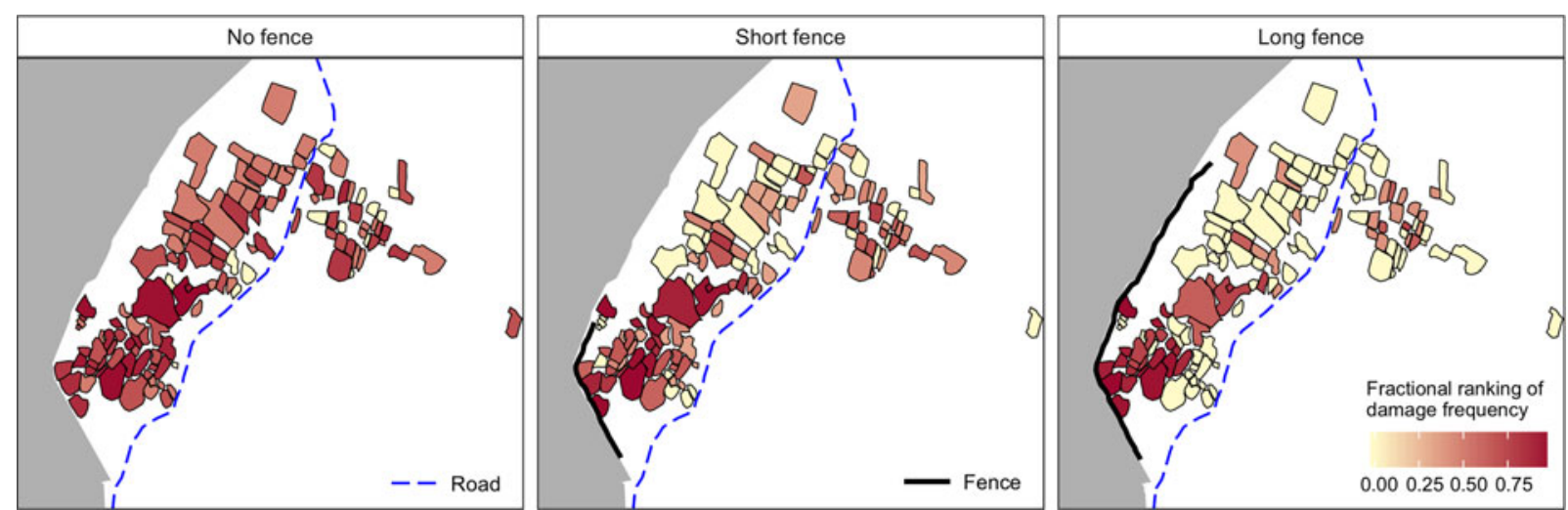

FIG. 3 Changes in the ranking of farm susceptibility to damage during an elephant visit for the three phases of the study: no beehive fence, short beehive fence, and long beehive fence.

gaps. Diligence of fence maintenance is therefore likely to be an important factor in fence success and we are monitoring whether beehive fence effectiveness increases when efficiency of closing gaps in the fence is improved.

The effectiveness of a beehive fence is further affected by the elephant bulls' tendency to forage on crops between dusk and dawn (Smit et al., 2017), when honeybees were less active at our site. There may be other site-specific factors to consider, including pollinator diversity, pesticide use, and the amount of wild flowers and nectar available, which in turn affect the number of occupied beehives. Nevertheless, our results show that the fence was effective even though no more than $56 \%$ of hives in the fence were occupied during the study period despite efforts to entice bees to occupy hives, such as placing wax inside the hives, planting flowers beneath them, and building thatch roofs above hives to shield them from rain and direct sun. Although none of the 87 hives in the extended portion of the long fence were occupied until September 2014, the frequency of elephant visits decreased further in the period with the long fence. This suggests that empty hives still deter elephants, consistent with findings by King et al. $(2011,2017)$, but the effectiveness of empty hives may depend on their proximity to occupied hives and on the elephants having previously had negative interactions with bees from occupied hives. We found that elephants crossed between two empty hives in two-thirds of fence breaches, but only $11 \%$ of elephant crossings occurred between occupied hives. Although this 
is partly affected by the number of hives occupied at any time, it provides evidence that elephants avoid the sound and/or smell of bees.

Our results demonstrate that beehives can be used to deter elephants but do not completely eliminate their use of crops. We also found evidence that elephants show aversion to roads during farm visits, suggesting that local anthropogenic alterations to the environment can have significant effects on the spatial patterns of human-elephant interactions (Blake et al., 2008). The placement of hives therefore requires care, as the positioning could unintentionally increase negative interactions. Our results suggest that in some cases a minimum effective fence length may be required to ensure that its effect of decreasing elephant visit frequency outweighs the effect of increasing the number of farms damaged during a visit.

Despite the mixed effectiveness of the beehive fences, elephant mortality from problem animal control and retaliatory killing declined to zero during this mitigation period, whereas previously $1-2$ elephants had been killed per year. Farmer-led mitigation appears to have helped increase local people's tolerance of elephant crop-use and changed the narrative from subjugated farmers waiting for the government to subsidize wildlife-related crop losses to empowered farmers taking on mitigation efforts themselves. Attitudes towards crop-using wildlife and community-led efforts to alleviate the problem shape the dynamics of human-wildlife interactions as much as the actual effectiveness of crop loss mitigation efforts. In the future, as the beehive method is adopted by other villages in the region, we plan to measure farmers' perceptions of elephants and associated crop losses before and after mitigation.

\section{Acknowledgements}

Fieldwork was funded by grants to the Southern Tanzania Elephant Program from the US Fish and Wildlife Service African Elephant Conservation Fund. Idea Wild contributed funding for field equipment. We thank Paulo Mndeme, Joseph Kidibule and Athumani Mndeme for assistance with collecting field data on crop damage and elephant crop use, Ponjoli Joram Kabepele, Fauna \& Flora International's Rapid Response Facility and Njokomoni farmers for being the impetus behind the first beehive fence, Raleigh International volunteers for their help with extending the beehive fence, Christopher Reusch for assistance with data processing and Phyllis Lee for her inputs, edits and insights, the Udzungwa Ecological Monitoring Centre for their cooperation and hospitality, and the Tanzania Forest Conservation Group and African Rainforest Conservancy for their support. Permissions were received from the Tanzania Wildlife Research Institute, Tanzania Commission for Science and Technology and Tanzania National Parks.

\section{Author contributions}

$\mathrm{KN}$ and TJ conceptualized the study. CPJS, JS, TJ and $\mathrm{KN}$ collected and processed the data. SAR analysed the data and all authors contributed to the writing.

\section{References}

Adjewodah, P., Beier, P., Sam, M.K., Mason, J.J. (2005) Elephant crop damage in the Red Volta Valley, north-eastern Ghana. Pachyderm, 38, 39-48.

Blake, S., Deem, S.L., Strindberg, S., Maisels, F., Momont, L., IsıA, I.-B. et al. (2008) Roadless wilderness area determines forest elephant movements in the Congo basin. PLoS ONE 3, e3546.

Bowkett, A.E., Rovero, F., \& Marshall, A.R. (2008) The use of camera-trap data to model habitat use by antelope species in the Udzungwa Mountain forests, Tanzania. African Journal of Ecology, $46,479-487$.

Chelliah, K., Kannan, G., Kundu, S., Abilash, N., Madhusudan, A., Baskaran, N., \& Sukumar, R. (2010) Testing the efficacy of a chilli-tobacco rope fence as a deterrent against crop-raiding elephants. Current Science, 99, 1239-1243.

Chiyo, P.I., Moss, C.J. \& Alberts, S.C. (2012) The influence of life history milestones and association networks on crop-raiding behavior in male African elephants. PLoS ONE, 7, e31382.

Graham, M.D. \& Ochieng, T. (2008) Uptake and performance of farm-based measures for reducing crop raiding by elephants Loxodonta africana among smallholder farms in Laikipia District, Kenya. Oryx, 42, 76-82.

Graham, M.D., Notter, B., Adams, W.M., Lee, P.C., \& Ochieng, T.N. (2010) Patterns of crop-raiding by elephants, Loxodonta africana, in Laikipia, Kenya, and the management of humanelephant conflict. Systematics and Biodiversity, 8, 435-445.

Gunn, J., Hawkins, D., Barnes, R.F.W., Mofulu, F., Grant, R.A., \& Norton, G.W. (2014) The influence of lunar cycles on crop-raiding elephants; evidence for risk avoidance. African Journal of Ecology, 52, 129-137.

Harchut, K., Standley, C., Dobson, A., Klahssen, B., Rambaud-Althaus, C., Althaus, F., \& Nowak, K. (2013) Over-diagnosis of malaria by microscopy in the Kilombero Valley, Southern Tanzania: an evaluation of the utility and cost-effectiveness of rapid diagnostic tests. Malaria Journal, 12:159, http://doi.org/10.1186/1475-2875-12-159.

Hedges, S. \& Gunaryadi, D. (2010) Reducing human-elephant conflict: do chillies help deter elephants from entering crop fields? Oryx, 44, 139-146.

Hoare, R. (2000) African elephants and humans in conflict: the outlook for co-existence. Oryx, 34, 34-38.

JADHAV, S. \& BARUA, M. (2012) The elephant vanishes: impact of human-elephant conflict on people's wellbeing. Health \& Place, 18, $1356-1365$.

JONES, T. \& NowAK, K. (2015) Elephant hideout: an unusual population of mountain-climbing elephants. In The Udzungwa Mountains - the Story of a Unique Rainforest in Eastern Africa (eds F. Rovero, N. Scharff, S. Brogger-Jensen \& F. Pagh Jensen) pp. 128-135. The Natural History Museum of Denmark, Copenhagen, Denmark.

Jones, T., Bamford, A.J., Ferrol-Schulte, D., Hieronimo, P., McWilliam, N. \& Rovero, F. (2012) Vanishing wildlife corridors and options for restoration: a case study from Tanzania. Tropical Conservation Science, 5, 463-474.

KaBEPELE, J.P. (2011) Employing novel approaches in the study of human-elephant conflicts along the eastern 
boundary of Udzungwa Mountains. MSc thesis. University of Poitiers, France.

KING, L.E. (2011) Beehive Fence Construction Manual. The Elephants and Bees Project \& Save the Elephants, Nairobi, Kenya. Http:// elephantsandbees.com/wp-content/uploads/2013/o8/BeehiveFence-Construction-Manual-2012.pdf [accessed o5 March 2018].

King, L.E., Douglas-Hamilton, I. \& Vollrath, F. (2007) African elephants run from the sound of disturbed bees. Current Biology, 17, R832-R833.

King, L.E., Douglas-Hamilton, I. \& Vollrath, F. (2011) Beehive fences as effective deterrents for crop-raiding elephants: field trials in northern Kenya. African Journal of Ecology, 49, 431-439.

King, L.E., Lala, F., Nzumu, H., Mwambingu, E. \& Douglas-Hamilton, I. (2017) Beehive fences as a multidimensional conflict-mitigation tool for farmers coexisting with elephants. Conservation Biology, 31 743-752.

King, L.E., Lawrence, A., Douglas-Hamilton, I. \& Vollrath, F. (2009) Beehive fence deters crop-raiding elephants. African Journal of Ecology, 47, 131-137.

Kioko, J., Muruthi, P., Omondi, P. \& Chyiyo, P.I. (2008) The performance of electric fences as elephant barriers in Amboseli, Kenya. South African Journal of Wildlife Research, 38, 52-58.

Lovett, J.C., Marshall, A.R. \& CARR, J. (2006) Changes in tropical forest vegetation along an altitudinal gradient in the Udzungwa Mountains National Park, Tanzania. African Journal of Ecology, 44 478-490.

Nelson, A., Bidwell, P. \& Sillero-Zubiri, C. (2003) A review of human-elephant conflict management strategies. People and Wildlife Initiative. Wildlife Conservation Research Unit, Oxford University, Oxford, UK.

Nowak, K., Jones, T. \& Lee, P.C. (2009) Using dung bolus diameter for age estimation in an unstudied elephant population in Udzungwa Mountains, Tanzania. Pachyderm, 46, 47-52.

Omondi, P., Bitok, E. \& Kagiri, J. (2004) Managing humanelephant conflicts: the Kenyan experience. Pachyderm, 36, 80-86.

Osborn, F.V. \& PArker, G.E. (2003) Towards an integrated approach for reducing the conflict between elephants and people: a review of current research. Oryx, 37, 80-84.

R Development Core Team (2015) R: A Language and Environment for Statistical Computing. R Foundation for Statistical Computing, Vienna, Austria. Http://www.R-project.org [accessed og February 2018].

RICHARDS, S.A. (2008) Dealing with overdispersed count data in applied ecology. Journal of Applied Ecology 45, 218-227.
Shemwetta, D.T.K. \& Kidegesho, J.R. (2000) Human-Wildlife Conflicts in Tanzania: What Research and Extension Could Offer to Conflict Resolution. Proceedings of the $1^{\text {st }}$ University Wide Conference, Morogoro, Tanzania, 3, 569-577.

Sitati, N.W. \& Walpole, M.J. (2006) Assessing farm-based measures for mitigating human-elephant conflict in Transmara District, Kenya. Oryx, 40, 279-286.

Sitati, N.W., Walpole, M.J., Smith, R.J. \& Leader-Williams, N. (2003) Predicting spatial aspects of human and elephant conflict. Journal of Applied Ecology, 4, 667-677.

Sitati, N.W., Walpole, M.J. \& Leader-Williams, N. (2005) Factors affecting susceptibility of farms to crop raiding by African elephants: using a predictive model to mitigate conflict. Journal of Applied Ecology, 42, 1175-1182.

Smit, J., Pozo, R.A., Cusack, J.J., Nowak, K., Jones, T. (2017) Using camera-traps to study the age-sex structure and behaviour of crop-using elephants in Udzungwa Mountains National Park, Tanzania. Oryx, https://doi.org/10.1017/Soo30605317000345.

Stephenson, P.J. (2007) WWF Species Action Plan: African Elephant, 2007-2011. WWF, Gland, Switzerland.

Sullivan, P. (2003) Intercropping principles and production practices. Agronomy Systems Guide. National Center for Appropriate Technology, Butte, USA

\section{Biographical sketches}

Ciska P. J. Scheijen conducts research on human-wildlife interactions and has studied primates and elephants in several African countries. She is currently examining human effects on the stress levels of wild giraffes in South Africa. SHANE A. Richards is a statistical ecologist whose research involves developing models of animal behaviour and ecosystem dynamics that address theoretical and applied problems, and confronting them with data. Josephine SMit works in elephant research and conservation as General Manager of the Southern Tanzania Elephant Program. She is currently researching elephants' responses to risk in the Ruaha-Rungwa ecosystem. TrEvor JONES has worked on conservation of endangered wildlife in southern Tanzania since 2002 and is currently Director of the Southern Tanzania Elephant Program. Katarzyna Nowak has researched the behaviour and conservation of primates and elephants in Tanzania and South Africa. She is presently a Fellow at The Safina Center, and scientific advisor to the Southern Tanzania Elephant Program. 